\title{
Optimization of Four Wheel Steering
}

\author{
R.Vigneshwaran", K.Saalai Chaithanyan ${ }^{\wedge *}$, N.Sathish ${ }^{\wedge}$ S.Prashanth^ and M.Parasaran^ \\ \#Assistant Professor, ^U.G Student, Department of Mechanical Engineering, Saranathan College Of Engineering, Panjappur, Tiruchirappalli, Tamil Nadu, \\ India
}

Received 20 Jan 2018, Accepted 25 March 2018, Available online 30 March 2018, Vol.6 (March/April 2018 issue)

\begin{abstract}
A Four wheel steering system also known as Quadra steering system. In this paper, both front wheel and rear wheels can be steered according to speed other vehicle and space available for turning. Quadra steer gives full size vehicle greater ease while driving at low speed, improves stability, handling and control at higher speed. Production-built cars tend to under steer or, in few instances, overseer. If a car could automatically compensate for an under steer overseer problem, the driver would enjoy nearly neutral steering under varying conditions.
\end{abstract}

Keywords: Four Wheel Steering, Quadra Steering System, Optimization, Turning Radius, Body roll, understeer/Oversteer.

\section{Introduction}

${ }^{1}$ Four-wheel systems is a serious effort on the part of automotive design engineers to provide near-neutral steering. This system finds application in off-highway vehicles such as forklifts, agricultural and construction equipment mining machinery in Heavy Motor Vehicles. It is also useful in passenger cars. It improves handling and helps the vehicle make tighter turns. This system is used to minimize turning radius. In that steering system, the all four wheels are to be steered according to the steer perform to drive towards left or right. Four-wheel steering, 4WS, also called rear-wheel steering or all-wheel steering, provides a means to actively steer the rear wheels during turning manoeuvres. It should not be confused with four-wheel drive in which all four wheels of a vehicle are powered. It improves handling and helps the vehicle make tighter turns. Production-built cars tend to under steer or, in few instances, over steer. If a car could automatically compensate for an under steer /over steer problem, the driver would enjoy nearly neutral steering under varying conditions. In most active four-wheel steering system, the rear wheels are steered by a computer and actuators, the rear wheels generally cannot turn as far as the front wheels. Some systems including Delphi's Quadra steer and the system in Honda's Prelude line allow the rear wheels to be steered in the opposite

*Corresponding author's ORCID ID: 0000-0002-6838-8457, DOI: https://doi.org/10.14741/ijmcr/v.6.2.6 direction as the front wheels during low speeds. This allows the vehicle to turn in a significantly smaller radius sometimes critical for large tucks or tractors and vehicles with trailers.

\section{Litrature Review}

This system of four wheel active steering system contributes to the fact that there are much room for improvements and there are failure modes that need attention for solving.

- In Phase and Counter Phase steering

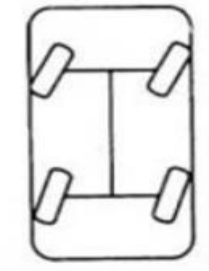

In-phase steering

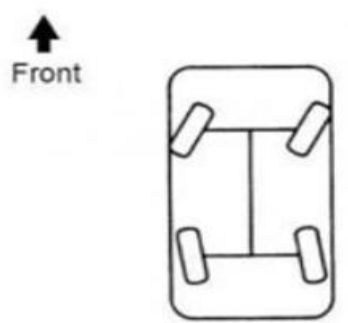

Counter-phase steering
Fig $1:$ In-Phase and Counter-Phase Steering

The 4WS system performs two distinct operations: inphase steering, whereby the rear wheels are turned in the same direction as the front wheels, and counter phase steering, whereby the rear wheels are turned in the opposite direction. 


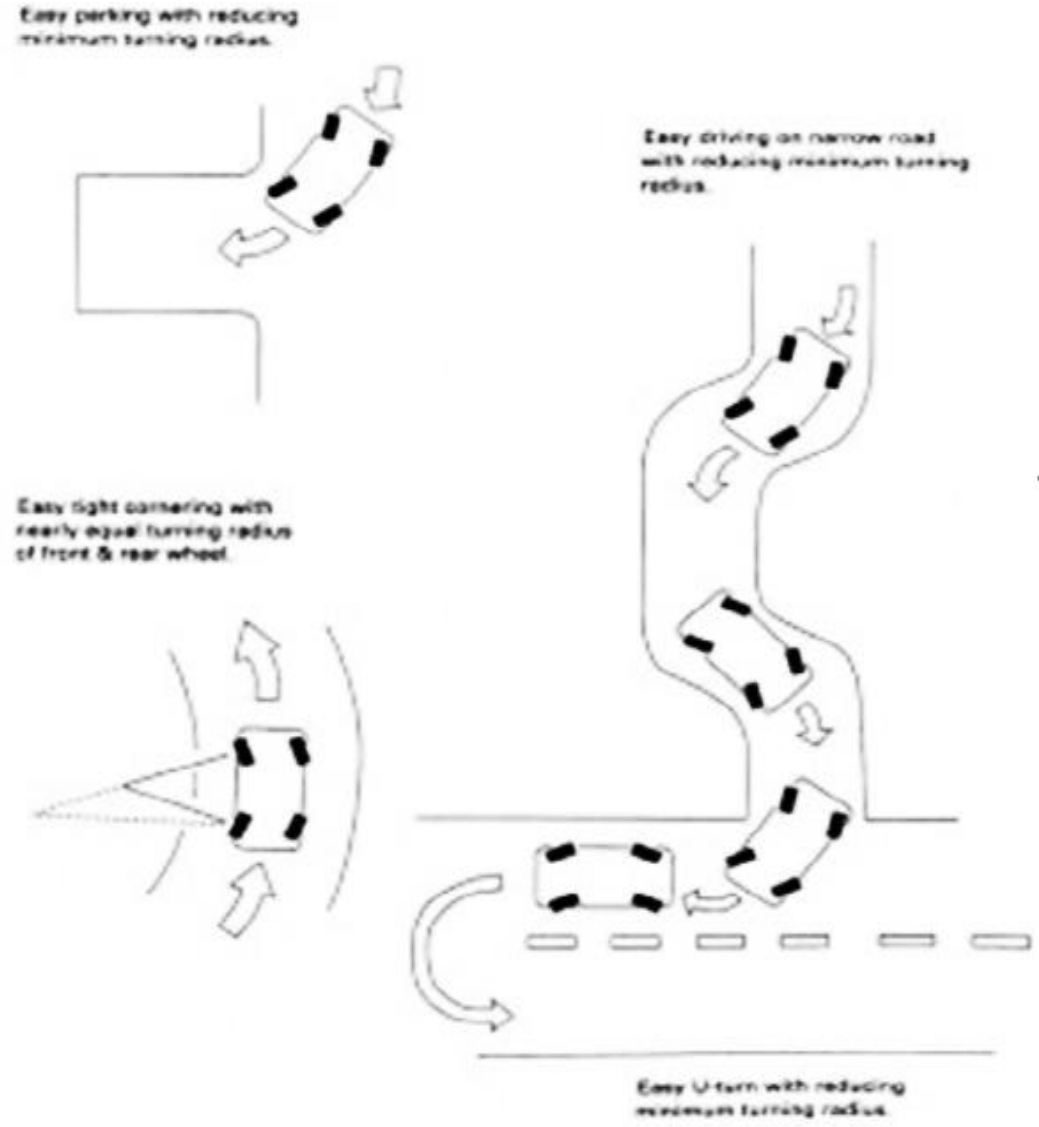

Fig 2 : Various modes of 4WS

- U Turn

General Theory of making a $U$ turn is by Minimising the turning radius in order to avoid the presence of over steer the counter phase steering is implied so as to ensure that there is a complete movement regarding the achievement of possible effortless $U$ turn.

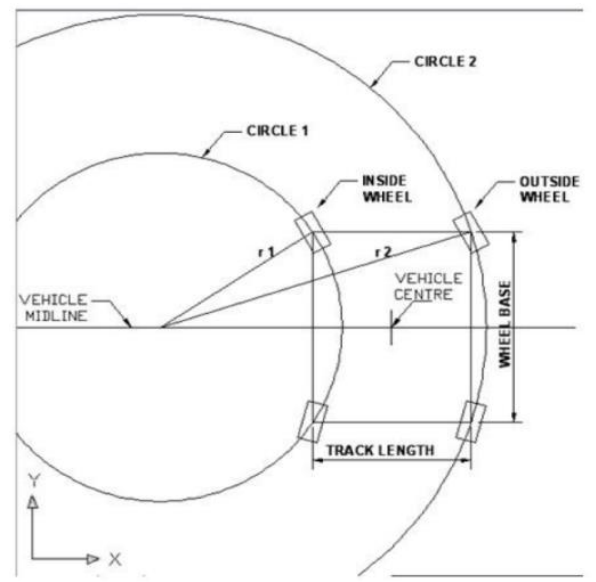

Fig 3 : Turning Radius for inner and outer Wheel

- $\quad$ Parallel Parking

Zero steer can significantly ease the parking process, due to its extremely short turning footprint. This is exemplified by the parallel parking scenario, which is common in foreign countries and is pretty relevant to our cities. Here, a car has to park it between two other cars parked on the service lane. This maneuver requires a three-way movement of the vehicle and consequently heavy steering inputs. Moreover, to successfully park the vehicle without incurring any damage, at least 1.75 times the length of the car must be available for parking for a two-wheel steered car.

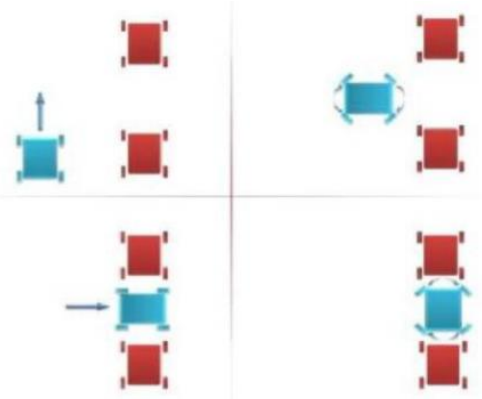

Fig 4 : Parallel Parking

- $\quad$ High speed Manuevering

High speed lane changing concept is driven around the fact that there should be an effortless driving created. When there is a sense of speed actuators that help in analysing the concept of speed changes, it sure helps around this besting out the outcome. 

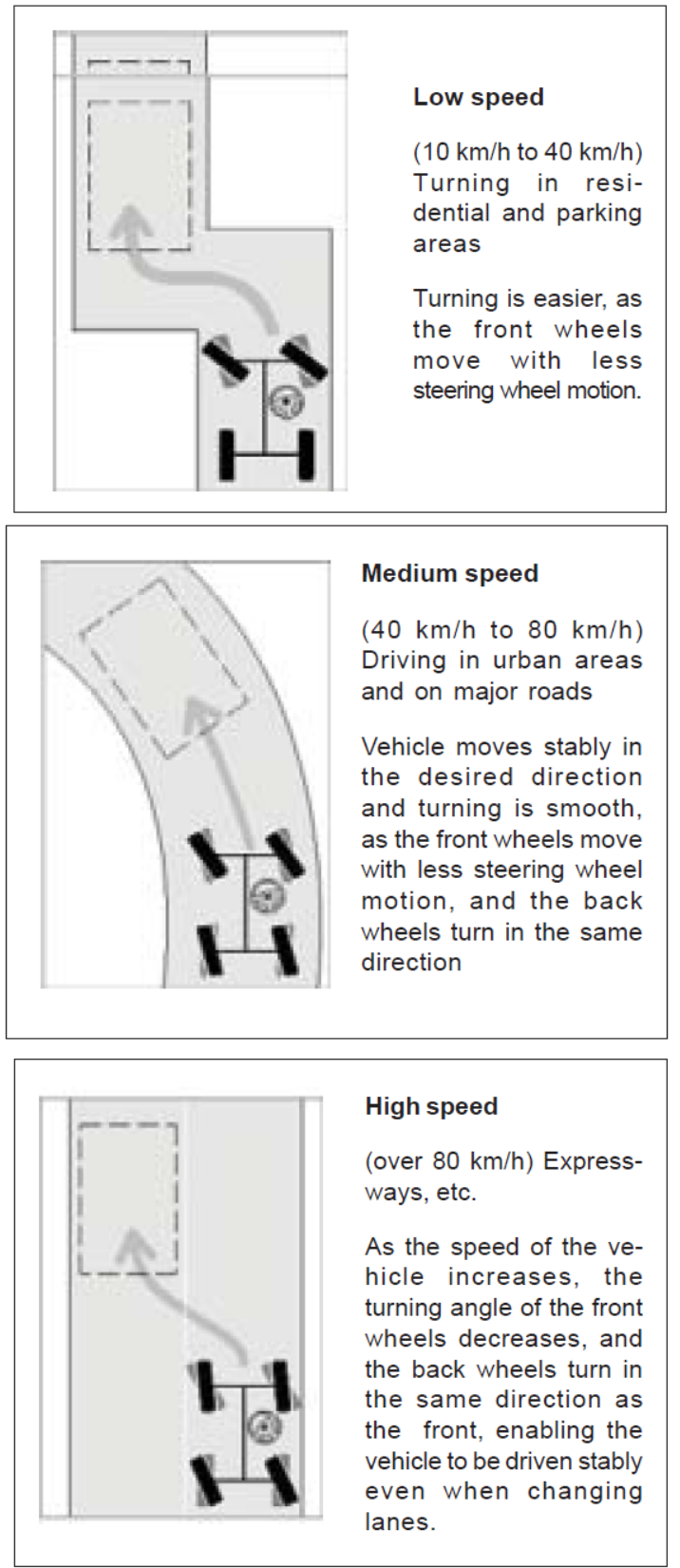

Fig 5 : Various Steering Controls

\section{Problem Definition}

Nowadays all vehicles use two wheel steering system, but the efficiency of the two wheel steering vehicle is proven that it is still low compared to the four wheel steering system car. So, this project is based on how to prove that the 4WS is better than 2WS in terms of Turning radius A vehicle with higher turning radius face difficulty in parking and low speed cornering due to its higher wheelbase and track width, but the passenger prefer the vehicle to be higher wheelbase and track width as it gives good comfort while driving and travelling. In this scenario four wheel steering will be effective as the turning radius will be decreased for the same vehicle of higher wheelbase. In this project a benchmark vehicle is considered and the four wheel steering is implemented without any change in dimensions of the vehicle and reduction in turning radius is achieved.

\section{- Methodology}

a) Literature review on effect of implementing four wheel steering system on turning radius and maneuverability of a car are carried out by referring journals, books, manuals and related documents.

b) The four wheel steering system model was built using ADAMS software and simulations carried out to know the turning radius and maneuverability.

c) Four wheel steering physical model was built considering same stub axle for front and rear.

d) Turning radius comparison were made between the physical model and the ADAMS model.

\section{Calculation}

The following Calculations are made with the fact that there were references made with respect to the benchmark vehicles

\section{Standard Specification Of Honda Civic}

\begin{tabular}{|c|c|c|}
\hline SI. No & Standards & Dimensions \\
\hline 1 & Wheel Base & $105.1^{\prime \prime}$ \\
\hline 2 & Steering Ratio & 14.89 \\
\hline 3 & Lock to lock turns & 2.87 \\
\hline 4 & Track width front and rear & $60^{\prime \prime}$ \\
\hline 5 & King Pin Centre to Centre Distance & $51^{\prime \prime}$ \\
\hline
\end{tabular}

Assumed values for Rack and Pinion:

No of teeth on Front Pinion $=20$

No of teeth on Rear Pinion $=16$

Module of Front and Rear Pinion $=1.25 \mathrm{~mm}$

No of teeth on Front and Rear Rack $=26$

Module of Rack $=1.25 \mathrm{~mm}$

These values on pinion are assumed so as to avoid interference with the rack and to obtain the required values of lock angles of all wheels.

\begin{tabular}{|c|c|c|c|c|}
\hline SI No & Particulars & $\begin{array}{c}\mathbf{2 0} \text { full } \\
\text { depth } \\
\text { involute } \\
\text { system }\end{array}$ & $\begin{array}{c}\text { For T=20 } \\
\text { (Front } \\
\text { Pinion) }\end{array}$ & $\begin{array}{c}\text { For T=16 } \\
\text { (Rear } \\
\text { pinion) }\end{array}$ \\
\hline 1. & Module & - & $1.25 \mathrm{~mm}$ & $1.25 \mathrm{~mm}$ \\
\hline 2. & Addendum & $1 \mathrm{~m}$ & $1.25 \mathrm{~mm}$ & $1.25 \mathrm{~mm}$ \\
\hline 3. & Dedendum & $1.25 \mathrm{~m}$ & $1.5625 \mathrm{~mm}$ & $1.5625 \mathrm{~mm}$ \\
\hline 4. & $\begin{array}{c}\text { Working } \\
\text { Depth }\end{array}$ & $2 \mathrm{~m}$ & $2.5 \mathrm{~mm}$ & $2.5 \mathrm{~mm}$ \\
\hline 5. & $\begin{array}{c}\text { Minimum } \\
\text { total depth }\end{array}$ & $2.25 \mathrm{~m}$ & $2.8125 \mathrm{~mm}$ & $2.8125 \mathrm{~mm}$ \\
\hline 6. & Tooth & $1.5708 \mathrm{~m}$ & $1.9635 \mathrm{~mm}$ & $1.9635 \mathrm{~mm}$ \\
\hline
\end{tabular}

We recall that the SINE on an angle is the ratio between the side opposite the angle and the hypotenuse. In shorthand, it looks as follows: 
$\operatorname{Sin} 13.64^{\circ}=\frac{y}{R}$

Where Ackerman Arm radius $\mathrm{R}=6$ " (Assumption) As you know, the name of the game in Algebra is getting the variable by itself, so...

$\operatorname{Arm} \operatorname{Base}(y)=6 \times \sin 13.64^{\circ}=1.4149$

Arm Base $(y)=1.4149^{\prime \prime}$

Verifying Arm Base (y)

$y=\frac{(\text { King pin } c-c \text { distance })-(\text { Length of the tie rod })}{2}$

$y=\frac{51-48.17}{2}=1.415^{\prime \prime}$

Arm Base $(y)=1.415^{\prime \prime}$

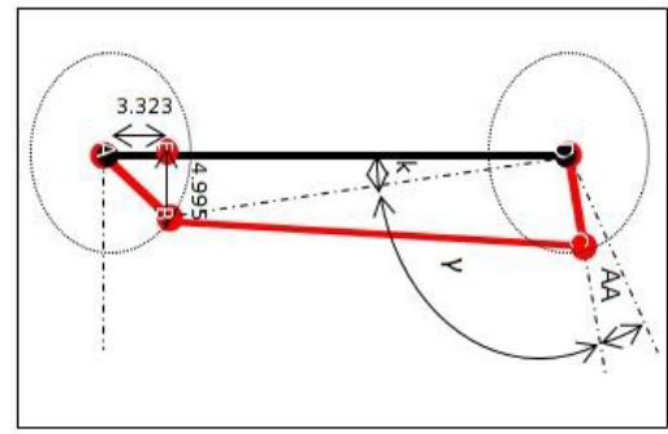

Fig 6 : Ackerman Steering angle calculation

Steer Angle $=\mathrm{k}+\mathrm{\gamma}+$ Ackerman Angle $-90^{\circ}$

Steer Angle $=5.980^{\circ}+88.71^{\circ}+13.64^{\circ}-90^{\circ}$

Steer Angle $=18.33^{\circ}$

This steer angle is related to Ackerman Angle, assuming that when left Ackerman Arm (AB) turns $20^{\circ}$ the transect $\operatorname{arm}(C D)$ turns $18.33^{\circ}$. This gives the approximate relation between the angles of turning of the wheels.

\section{Honda Civic specification}

\begin{tabular}{|c|c|}
\hline Particulars & Dimensions \\
\hline Turning Circle Radius (R) & $5.394 \mathrm{~m}$ \\
\hline Weight of the car (W) & $1250 \mathrm{Kg}$ \\
\hline Weight Distribution & $60: 40$ (Front : Rear) \\
\hline Wheelbase (L) & $2.669 \mathrm{~m}$ \\
\hline Track Width $\left(\mathrm{t}_{\mathrm{w}}\right)$ & $1.524 \mathrm{~m}$ \\
\hline
\end{tabular}

\section{- Turning Circle Radius}

By Ackerman Mechanism,

$\operatorname{Sin}\left(\alpha+\theta_{\text {if }}\right)=\frac{y+X}{R}$

Where, $\alpha=$ Ackerman Angle $=13.64^{\circ}$

$\theta_{\text {if }}=$ Inside Lock Angle

$\mathrm{Y}=$ Arm Base $=1.415^{\prime \prime}$

$X=$ Linear Displacement of rack for one rotation of pinion

$\mathrm{R}=$ Ackerman Arm Radius $=6 "$

Therefore, Inside Lock Angle of Front Wheel is $35.16^{\circ}$

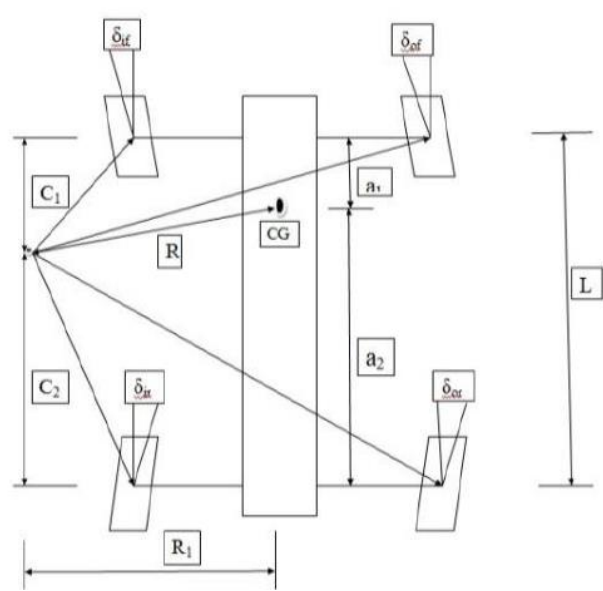

Fig 7 : Turning Angles

- Calculation of position of Centre of Gravity with respect to rear axle

From the benchmark vehicle (Honda Civic) we know that turning radius is $5.394 \mathrm{~m}$.

We know that, $R^{2}=a^{2}+R_{1}{ }^{2}$

Where,

$\mathrm{R}=$ Turning radius of the vehicle $=5.394 \mathrm{~m}$

(Standard Specification of Civic)

$\mathrm{a}_{2}=$ Distance id CG from rear axle

$\mathrm{R}_{1}=$ Distance between Instantaneous centre and the axis of the vehicle

To find $\mathrm{a}_{2}$

$\mathrm{W}_{\mathrm{f}}=\frac{W \times a_{2}}{L}$

Where,

$\mathrm{W}_{\mathrm{f}}=$ Load on front axle $=750 \mathrm{Kg}$ (On bases weight distribution)

$\mathrm{W}=$ Total weight of car $=1250 \mathrm{Kg}$

$\mathrm{L}=$ Wheelbase $=2.669 \mathrm{~m}$

Therefore,

$\mathrm{a}_{2}=1.60 \mathrm{~m}$

\section{- Calculation of Turning Angles}

Steering ratio of a car is calculated by the following formula:

$\mathrm{R}=\frac{s}{\sqrt{2-2 \cos (2 a / n)}}$

Where, $\mathrm{R}=$ radius of curvature (same as units of wheelbase) $=1.92 \mathrm{~m}=75.59^{\prime \prime} \mathrm{s}=$ wheelbase $=105.1^{\prime \prime} \mathrm{a}=$ steering wheel angle $=360$ o (assumed for one rotation of steering wheel) $n=$ steering ratio (Eg. for 16:1 its 16 ). 
Substituting the value of $a_{2}$ in the above equation $\mathrm{R}_{1}=5.15 \mathrm{~m}$

$$
\begin{aligned}
& 75.59=\frac{105.1}{\sqrt{2-2 \cos (720 / n)}} \\
& 1.39=\sqrt{2-2 \cos 720 / n} \\
& 1.9321=2-2 \cos 720 / n \\
& 0.069=2 \cos ^{720 / n} \\
& \cos ^{720} / n=0.034 \\
& \frac{720}{n}=88.051 \\
& \mathbf{n}=\mathbf{8 . 1 7 7}
\end{aligned}
$$

\section{Design Model}

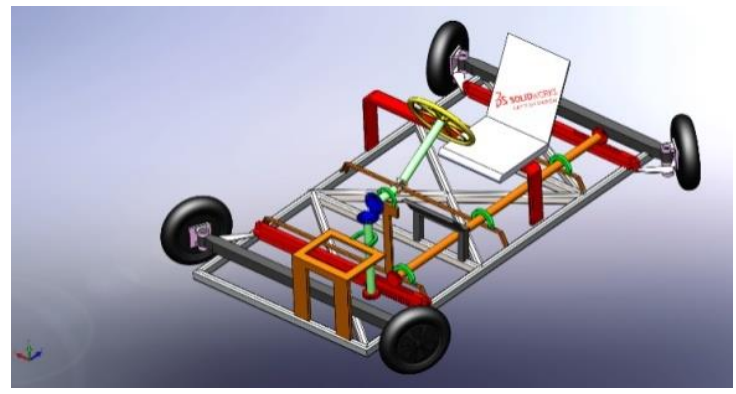

Fig 8 : Solidworks Model

Thus, the steering ratio of our car is $8.177: 1$, i.e. for 8.1770 of rotation of steering wheel the tire is turned by an angle of 1 Degree. Thus from the above obtained value of Steering Ratio, we can conclude that driver has to apply less effort to turn the car, giving much better maneuverability and control on the car.

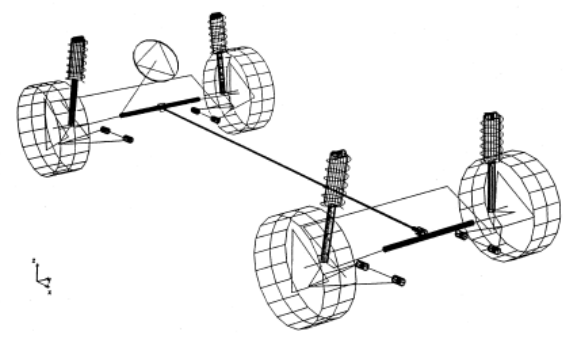

Fig 9 : ADAMS Steering model

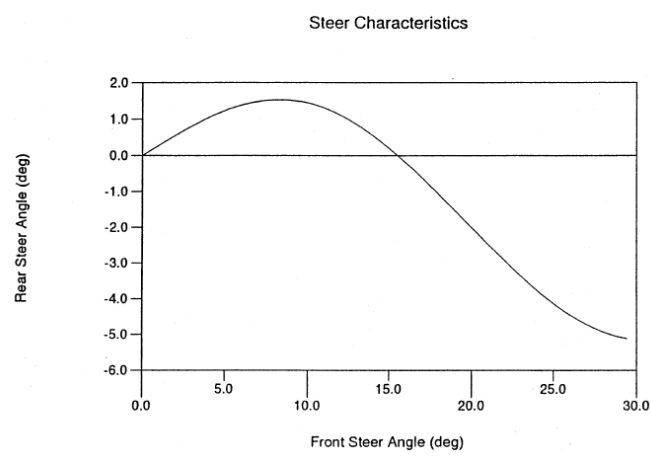

Fig 10 : Characteristic curve of Steer Angle
The Above suggested method of model behaviour drives to the fact that there can be various and possible nodes of failure which can suite the fact that this can suffice most of the fail safe measures while there is an actual manufacturing is made.

\section{Fame Analysis}

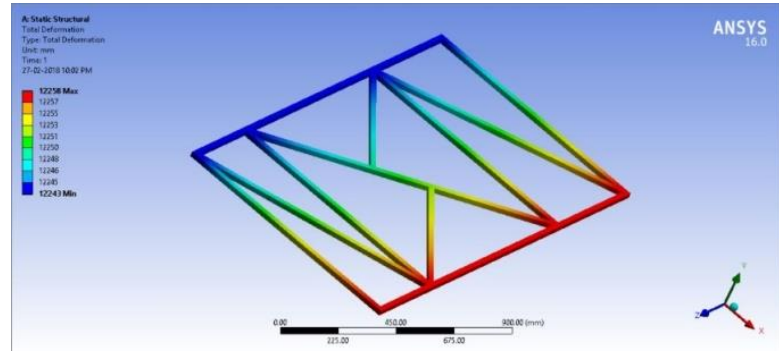

Fig 11 : Total Deformation of the Frame

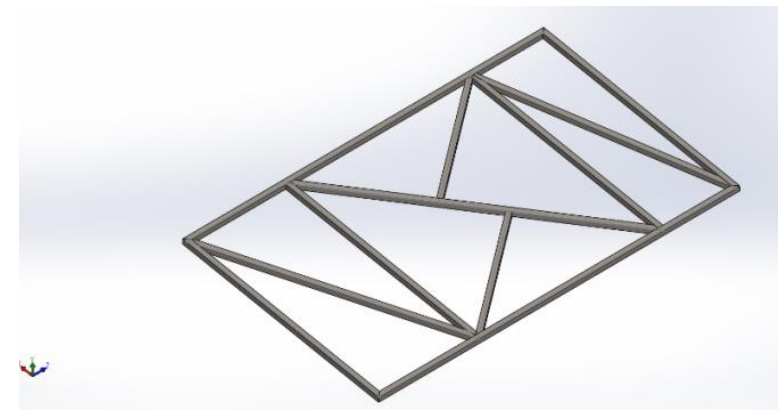

Fig 12 : Von Mises Stress for the frame

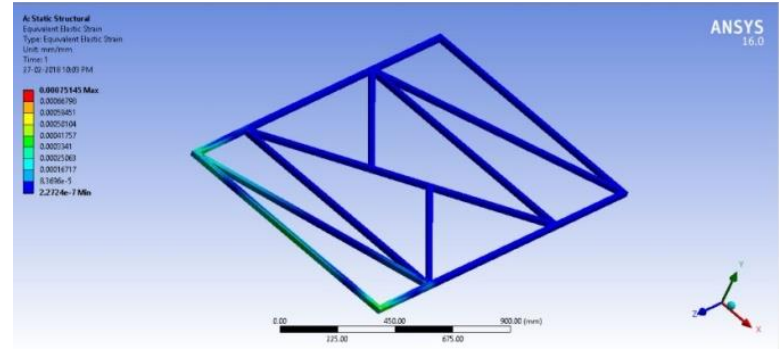

Fig 13 : Designed Frame

\section{Results Discussion}

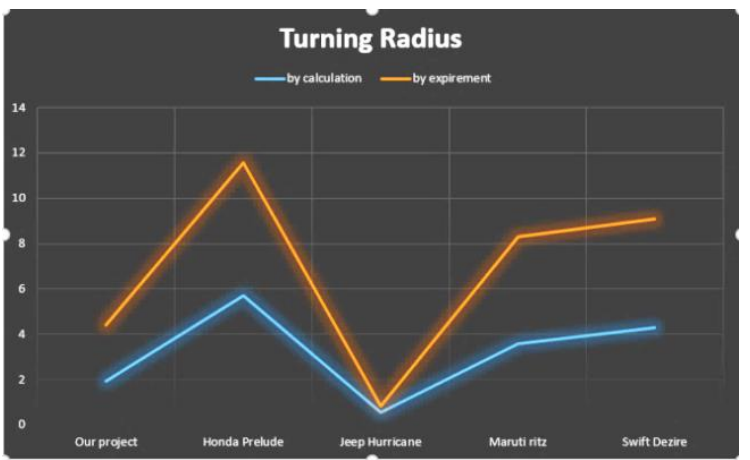

Fig 14 : Turing Radius Comparison for various 4WS 


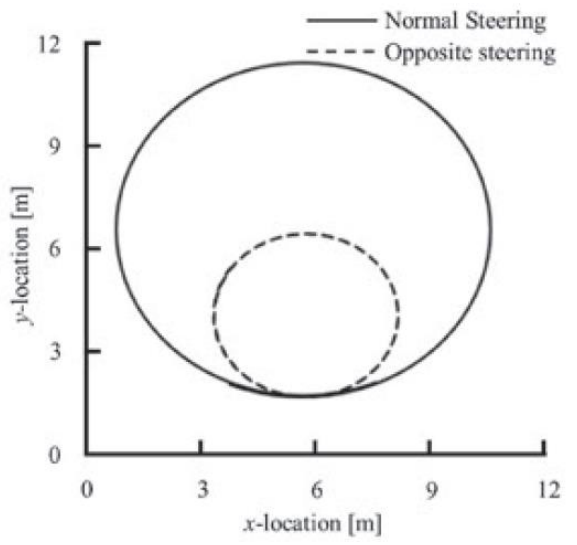

Fig 15 : ADAMS Simulated Vehicle Loction

Figure shows the simulated trajectories in normal steering and opposite steering. H. S. Kim, S. S. You, "Estimation of Vehicle Sideslip Angle for Four-Wheel Steering, Passenger Cars", Transactions on Control, Automation and Systems Engineering, 3, 71-76,2001. We use this result to make a comparison between normal and opposite steering cornering. From the results above, we confirmed that the turning radius of opposite steering is smaller than normal steering. Normal steering takes longer distance in a cornering. Hence, we can conclude that opposite steering has higher cornering performance.

In case of normal steering, cornering force is only produced at front tires. The rear tires will only follow the movement of front tires. However, for opposite steering, Cornering force is produced at both front and rear tires.

Four wheel steering is a relatively new technology, that imposes maneuverability in cars trucks and trailers .in standard two wheels steering vehicles, the rear set of wheels are always directed forward therefore and do not play an active role in controlling the steering in four wheel steering system the rear wheel can turn left and right . To keep the driving controls as simple as possible.
The aim of 4WS system is a better stability during overtaking manoeuvres, reduction of vehicle oscillation around its vertical axis, reduced sensibility to lateral wind, neutral behaviour during cornering, etc., i.e. improvement of active safety.

\section{Conclusion}

As per the focus of the project we have created an innovative 4 wheel active steering mechanism which is feasible to manufacture, easy to install and highly efficient in achieving in-phase and counter-phase rear steering with respect to the front wheels.

This system assists in high speed lane changing and better cornering. It combats the problems faced in sharp turning. It reduces the turning circle radius of the car and gives better maneuverability and control while driving at high speeds, thus attaining neutral steering.

\section{Reference}

[1]. K. Lohith, Dr. S. R. Shankapal, \& Mr. H. Monish Gowda "Development of Four Wheel Steering System for a Car," SAS Tech Journal, vol. 12, pg. 90-97, Issue 1, April 2013.

[2]. Honda official website http://automobiles.honda.com/ civicsedan/specifications.aspx

[3]. Dr. Kirpal Singh "Automobile Engineering" Standard Publishers Distributors, vol. 1, 12th Edition, 2011.

[4]. V. B. Bhandari "Design of Machine Elements" McGraw Hill Education India Pvt. Ltd., vol. 3, 11th Edition, 2013.

[5]. Atinder Singh "Ackerman Steering Formula Derivation", http://www.scribd.com/doc/58682411/AckermanSteering-Formula-Derivation, June 2011.

[6]. M. Kreutz, M. Horn, J. Zehetner, "Improving vehicle dynamics by active rear wheel steering systems", Vehicle System Dynamics, 47(12),1551-1564, 2009

[7]. R. B. Gupta, "Automobile Engineering, Satya Prakashan", New Delhi, pp 3-8 and 571-579, 2007

[8]. http://auto.howstuffworks.com/jeep-hurricane2.html

[9]. Ministry of Land, Infrastructure and Transport

[10]. Department Municipal Affairs Bureau, Automobiles of Japan, "Guideline for introduction to Ultra-Compact Mobility, June (2013) http://www.mlit.go.jp/ common/000212867.pdf 